\title{
PARQUE PELOTENSE: UM ESPAÇO DE LAZER EM PELOTAS/RS*
}

\author{
Dalila Rosa Hallal* \\ Dalila Müller**
}

\begin{abstract}
Resumo
Neste artigo analisamos o surgimento e a trajetória do Parque Pelotense e sua importância para o lazer em Pelotas, no período de 1883 a 1916. Adotamos a concepção de lazer de Corbin (2001), que o considera como a liberdade de usar o tempo livre para distrações ou ocupações a que as pessoas se entregam de livre vontade, sendo muito valorizado pelas elites urbanas do século XIX. Neste período, há uma busca pelos espaços de natureza, dentre eles, os parques. Estes novos hábitos de convívio respondem a um processo de valorização da natureza como um espaço não submetido à ordem e à intervenção humana $\mathrm{e}$ importante para a saúde. As fontes foram bibliográficas e documentais, principalmente os jornais diários de Pelotas. Constatamos que o Parque foi um dos principais espaços de natureza para o lazer dos pelotenses e de visitantes, um espaço capaz de estabelecer relações sociais mediante práticas esportivas, educativas, culturais, artísticas e ambientais. O Parque Pelotense foi um local de lazer completo para a época, com atividades ao ar livre indo ao encontro da necessidade de aproximar a população da natureza. Com o passar dos anos, foi abandonado e sua área loteada. Atualmente não resta mais nada do Parque. Desse modo, 0 registro de sua história e memória enquanto espaço de lazer é relevante na medida em que contribui para as discussões atuais sobre a necessidade de ampliação de áreas verdes para o lazer em Pelotas e futuras ações.
\end{abstract}

Palavras-chave: História; Parques Urbanos; Lazer; Parque Pelotense; Pelotas.

\section{PARQUE PELOTENSE: A LEISURE SPACE IN PELOTAS/RS}

\begin{abstract}
In this paper we analyze the trajectory of Parque Pelotense and its importance for leisure in Pelotas, in the period from 1883 to 1916. We adopt Corbin's (2001) conception of leisure, which considers it the freedom to use free time for distractions or occupations to which people indulge freely, being highly valued by the urban elites of the nineteenth century. During this period, there is a search for the spaces of nature, among them, the parks. These new living habits respond to a process of valuing nature as a space not subject to order or to human intervention and which is also important for health. The sources were bibliographical and documental, mainly the daily newspapers of Pelotas. We note that the park was one of the main natural areas for recreation of the people of Pelotas and visitors, a space capable of establishing social relations through sports, educational, cultural, artistic and environmental activities. Parque Pelotense was a complete leisure place at the time, with outdoor activities meeting the need to bring the population closer to nature. Over the years, it was abandoned and its area is allotted. Currently there is nothing left of it. Thus, the record of the park's history and memory as a leisure space is relevant in that it contributes to the current discussions about the need to expand green spaces for leisure in Pelotas and future actions.
\end{abstract}

Keywords: History; Urban Parks; Leisure; Parque Pelotense; Pelotas.

\section{PARQUE PELOTENSE: UN ESPACIO DE ESPARCIMIENTO EN LA CIUDAD DE PELOTAS/RS} cia para el esparcimiento en la ciudad de Pelotas desde 1883 hasta 1916. Adoptamos la concepción de esparcimiento de Corbin (2001), que lo considera como la libertad de utilizar el tiempo libre para distracciones u ocupaciones a las que las personas se entregan de libre voluntad, lo que fue muy valorado por las elites urbanas del siglo XIX. En este período, hay una búsqueda por los espacios naturales, entre ellos los parques. Estos nuevos hábitos de convivencia responden a un proceso de valoración de la naturaleza como un espacio no sometido al orden y a la intervención humana e importante para la salud. Las fuentes fueron bibliográficas y documentales, principalmente los periódicos diarios de la ciudad de Pelotas. Concluímos que el Parque fue uno de los principales espacios naturales para el esparcimiento de los pelotenses y visitantes, un espacio capaz de establecer relaciones sociales por medio de prácticas deportivas, educativas, culturales, artísticas y ambientales. El Parque Pelotense fue un local de esparcimiento completo para la época, con actividades al aire libre que satisfacían la necesidad de acercar los ciudadanos a la naturaleza. Con el paso de los años, fue abandonado y su área loteada. Actualmente, ya nada queda del Parque. De esa manera, el registro de la historia y de la memoria del Parque como espacio de esparcimiento es importante, una vez que contribuye para las discusiones actuales sobre la necesidad de ampliación de áreas verdes para esparcimeinto en la ciudad de Pelotas y para futuras acciones.

Palabras Clave: Historia; Parques Urbanos; Esparcimiento; Parque Pelotense; Ciudad de Pelotas.

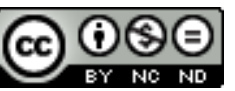

Licenciada por Creative Commons Atribuição Não Comercial / Sem Derivações/ 4.0 / Internacional

\footnotetext{
* Doutora em História/PUCRS. Mestre em Turismo/UCS. Bacharel em Ciências Sociais/UFPel. Professora associada da Universidade Federal de Pelotas. Pesquisa sobre história, turismo e patrimônio. CV: http://lattes.cnpq.br/4606760006124679. Universidade Federal de Pelotas, Faculdade de Administração e de Turismo, Departamento de Turismo. Rua Gomes Carneiro, ñ 1, Campus Porto, CEP 96010-610, Pelotas/RS, Brasil. [dalilahallal@gmail.com ]

** Doutora em História/UNISINOS. Mestre em Turismo/UCS. Bacharel em Ciências Sociais/UFPel. Professora associada da Universidade Federal de Pelotas, atuando no Curso de Bacharelado em Turismo e no Programa de Pós-Graduação em História - UFPel. Pesquisa e escreve sobre história e turismo, com ênfase nos seguintes temas: lazer e sociabilidade, hotelaria e turismo em Pelotas e história de Pelotas. CV: http://lattes.cnpq.br/3450137421308599. Universidade Federal de Pelotas, Faculdade de Administração e de Turismo, Departamento de Turismo. Rua Gomes Carneiro, nº 1, Campus Porto, CEP 96010-610 Pelotas/RS, Brasil. [ dalilam2011@gmail.com ]
} 


\section{INTRODUÇÃO}

"Mas o melhor passeio, o preferido, era a visita ao Parque Souza Soares [Pelotense]. Até lá se levava obrigatoriamente o forasteiro, como um indispensável cartão de visita".

Mário Osório Magalhães

É no século XIX, diante de um forte incremento populacional nas cidades que largos e praças, espaços, de tamanho bastante reduzido, não mais atendem às necessidades da população, que buscam diferentes espaços para o lazer, incluindo áreas verdes. A partir do romantismo a natureza passa a ser valorizada. Segundo Carvalho (2009, p. 141), "Essas sensibilidades nasceram à medida que se evidenciavam os efeitos da deterioração do meio ambiente e da vida nas cidades, causada pela revolução industrial." Nesse contexto, são criados os parques urbanos visando minimizar a deterioração da qualidade de vida no meio urbano, bem como proporcionar áreas de lazer à população.

Neste estudo, o lazer é entendido como a liberdade de usar o tempo livre para distrações ou ocupações a que as pessoas se entregam de livre vontade (CORBIN, 2001). Entre os múltiplos espaços de lazer existentes no município de Pelotas no final do século XIX, os parques urbanos são lugares interessantes para pensar a relação entre as formas desta manifestação e o desenvolvimento da cidade.

Tal como o lazer, o parque urbano é um produto da cidade moderna. Nasceu, a partir do século XIX, da necessidade de dotar as cidades de espaços adequados para atender a uma nova demanda social. Estes locais teriam por função conduzir os sujeitos à sensação de descanso e de entretenimento, seja pela recriação do contato com a natureza, seja pela oferta de atividades dotadas de elementos lúdicos.

Os parques urbanos são espaços públicos bastante representativos na socialização da cidade, por oferecer diversas atividades - esportivas, culturais, artísticas, educativas e ambientais - capazes de estabelecer relações sociais entre os citadinos e representam espaços com presença da natureza que propiciam a contemplação/fruição no meio urbano.

Na virada do século XIX para o XX, Pelotas vivia uma época de transformações infraestruturais, ainda em função da prosperidade econômica obtida entre 1860 e 1890, momento em que as charqueadas trouxeram grandes recursos econômicos para a região. Nesta cidade convivia uma riqueza imponente, que se expressava por meio de seus casarios e uma pobreza marcante, que excluía de uma sobrevivência digna milhares de pessoas, em sua maioria, negros recém libertos e imigrantes pobres.
A opulência de Pelotas durante as décadas finais do século XIX tem sido relatada por vários autores, que definiram a cidade tendo como marca a importância dos barões do charque, uma vez que no auge da sua produção (18601890) a cidade contou com cerca de 40 charqueadas, que além de proporcionarem um grande crescimento econômico para a região, favoreceram a construção de uma nova infraestrutura, que se relacionava a obras para o melhoramento de águas e instalação de esgotos, aumento de iluminação pública, novos meios de transporte, além das transformações no que diz respeito à cultura e ao lazer, com a inauguração da Biblioteca Pública Pelotense em 1875 e a proliferação de clubes e associações recreativas, culturais, étnicas, bailantes, carnavalescas, literárias, religiosas e a existência de um número impressionante de jornais diários, além de muitos semanários. Todo este progresso, no entanto, estava ainda circunscrito a pequenos espaços territoriais, geralmente no centro da cidade e a cultura e o lazer se destinava a poucas parcelas da população. (GILL, 2008, p.1).

Nesse momento de modernidade, de transformações e progresso da cidade, na chamada Belle Époque de Pelotas, que ocorreu, entre os anos de 1890 e 1927, justamente por ter sido uma época de efervescência de fatos culturais nesta localidade, a explosão da imprensa, na segunda metade do século XIX, o surgimento da Guarani Films em 1914, a reinauguração do Theatro Sete de Abril em 1916, a inauguração do Theatro Guarany em 1921 e a proliferação do comércio em diversos segmentos (MARRONI, 2008, p.27). Importante citar que foi ao redor deste contexto da Belle Époque Pelotense que foi inaugurado o Parque Pelotense, também conhecido como Parque Souza Soares, no final do século XIX.

Além da residência do proprietário e do Laboratório Farmacêutico, na área do Parque de aproximadamente 60 hectares, existiam inúmeras plantas, árvores e flores, bosques, avenidas arborizadas, lagos, praças, caramanchões, coretos, aparelhos de ginástica, ringue de patinação, bailes, música, entre outras atividades recreativas. Em função disso, se tornou ponto de atração para residentes e visitantes, sendo considerado "o primeiro centro turístico do estado do Rio Grande do Sul" (SOARES; REIS, 2010).

Impossivel analisar espaços de lazer em Pelotas no século XIX, sem falar no Parque Pelotense, o qual transformou a vida dos pelotenses, dando-lhes um lugar de diversão e lazer. Assim, a escolha deste parque deveu-se ao seu caráter precursor em Pelotas o que, de forma inerente, se configura como um 
elemento de grande importância na história da cidade. Conhecido posteriormente como Parque Souza Soares, o Parque Pelotense foi inaugurado em 1883 pelo seu fundador José Álvares de Souza Soares (mais conhecido como Visconde de Souza Soares).

Assim, tomamos como objeto de estudo o Parque Pelotense, uma vez que podemos encontrar nesta trajetória elementos interessantes para a discussão sobre os papéis desempenhados pelos espaços dos parques urbanos nas práticas de lazer dos sujeitos no seu tempo livre.

O estudo trata-se de uma pesquisa de cunho qualitativo que busca investigar e registrar a história do Parque Pelotense, identificando o surgimento e a trajetória de seu uso para o lazer em Pelotas, no período de 1883, quando é inaugurado, até 1916, quando é arrendado, não sendo mais dirigido pela família Souza Soares.

Realizou-se uma pesquisa bibliográfica e documental, onde buscou-se uma fundamentação teórica do objeto de estudo e um levantamento de materiais a partir dos quais foram feitas as análises. $\mathrm{A}$ pesquisa documental foi realizada no acervo da Biblioteca Pública Pelotense; no Instituto Histórico e Geográfico de Pelotas e do Rio Grande do Sul; no acervo fotográfico Nélson Nobre Magalhães Memórias de Pelotas do Laboratório de Acervo Digital da Universidade Católica de Pelotas, entre outros. As principais fontes foram os jornais diários que estavam em circulação no período estudado, entre eles, o Correio Mercantil, Onze de Junho, Arauto, Opinião Pública, Zé Povinho e Diário Popular.

A inauguração do Parque Pelotense ocorreu em fevereiro de 1883, quando foi aberto ao público, proporcionando inúmeras atividades de lazer junto à natureza, possibilitando o contato da elite e dos visitantes que aqui chegavam com áreas verdes, aspecto bastante valorizado no período de funcionamento do Parque.

As práticas de lazer eram diversas, contemplando aspectos esportivos, educacionais, culturais, artísticos e ambientais. Em 1916, com a morte de seu fundador em 1911, é arrendado, não sendo mais administrado pela família Souza Soares. Após anos de decadência, a área do Parque foi loteada pelos descendentes.

0 artigo está estruturado da seguinte forma: 0 referencial teórico consistiu na revisão bibliográfica dos seguintes conceitos basilares: lazer e parque, e discorre sobre o histórico dos parques urbanos como espaços de natureza na cidade e para as práticas de lazer e contemplação no meio urbano. Logo depois, apresenta os caminhos metodológicos que auxiliaram nas reflexões e discussões utilizadas ao longo da pesquisa. Posteriormente, analisa a história e as práticas de lazer do Parque Pelotense em Pelotas a luz da teoria.

\section{REVISÃO TEÓRICA}

\subsection{Lazer e Parques Urbanos}

A criação de espaços de lazer em Pelotas no século XIX era destinada para uma elite. Corbin (2001, p. 63) considera que "no seio das elites do século XIX, o lazer se acha valorizado.". Essas elites, incluindo a elite pelotense, dispunham de um tempo livre, sem significar que eram ociosas, mas que evitavam o "vazio das horas".

A possibilidade de dispor de um tempo livre era considerada "a recompensa e o privilégio de um nascimento nobre, a marca de uma superioridade pessoal." (PORTER, 2001, p. 21). 0 uso do tempo livre para o lazer se constituía em um elemento de diferenciação social.

Conforme Gomes (1992 p. 56-57),

As novas práticas, que acompanham as mudanças sociais, impõem novas representações acerca das formas de interacção social, fundindo-se, no entanto, com representações tradicionais dos modos de estar em sociedade e de utilizar os espaços e os tempos do ócio. Finalmente, o ócio revela-se como signo e símbolo distintivos, como uma das formas de a burguesia sublinhar a sua diferença relativamente aos que não lhe têm acesso. Não tendo adquirido um estatuto e diferença pelo nascimento, para a burguesia em afirmação política e social torna-se indispensável integrar a ostentação não apenas nas aparências, como também nos comportamentos e práticas diárias.

Assim, a noção de lazer é entendida como a "liberdade de tempo" utilizado para distrações ou ocupações a que as pessoas se entregam de livre vontade, "e não como sequência temporal sem trabalho". A disponibilidade "não é sinônimo de inutilidade" e "se encontra associada à despesa sumptuária, é além disso um marcador social" (CORBIN, 2001, p. 62-3).

A elite é obrigada a "empregar o tempo e tem que encontrar numa ocupação uma razão para viver. Mas as actividades a que se consagra[m] respondem imperativamente a três condições: tem que ser voluntárias, honoríficas e desinteressadas." Essas atividades não devem interferir na "independência nem [n]a capacidade de dispor livremente do tempo" (CORBIN, 2001, p. 63). 
Na segunda metade do século XIX o tempo livre começa a ser utilizado em atividades de lazer em espaços de natureza. Segundo Carvalho (2009) a cultura de valorização da natureza vai se reafirmar com o movimento romântico europeu do século XIX.

A busca pelos espaços de natureza define novas temporalidades urbanas, "em que a natureza emerge como espaço sanitário e como lugar possível de um lazer regenerador e revigorante." (CSERGO, 2001, p. 189). Como afirma Carvalho (2009) o sentimento de apreciação da natureza pode ser considerado uma sensibilidade burguesa, pois é essa parcela da população que dispõe de tempo e recursos para cultivar os novos hábitos de convívio e admiração da natureza. Assim, é a elite pelotense que vai usufruir desses novos espaços de lazer.

A partir do romantismo, a natureza passa a ser um valor desejado e valorizado pela elite. Nessa perspectiva, "[...] fazer passeios ao ar livre, piqueniques nos bosques, ouvir música em ambientes naturais, ir ao campo nos finais de semana, empreender, observar pássaros, são fartamente registrados pela literatura e pintura dos séculos XVIII e XIX." (CARVALHO, 2009, p. 143).

Os parques urbanos representam a iniciativa de construção de espaços com a presença de natureza na cidade voltados ao lazer. Os jardins remetem à tentativa de resgatar o paraíso perdido, tendo-se em vista que tanto os jardins públicos quanto os privados proporcionam a contemplação/fruição, o descanso, o flanar ou, simplesmente, o contato com a natureza. Posteriormente, os parques urbanos continuam com essa função, acrescida da ideia de representar um espaço como fragmento de natureza no meio urbano e a prática de lazer - socialização - nas cidades (MELO, 2013).

Segundo Segawa (1996, p. 23) "na Europa dos séculos 17 e 18, manifestações de apreço com a natureza e a paisagem afloravam com maior intensidade." Tornou-se um hábito cotidiano o contato com a natureza pelo fato dela proporcionar um devaneio íntimo, privacidade, meditação, repouso e harmonia. Os jardins e os parques públicos, com a presença da natureza, se destacam como criações marcantes na urbanização e podem ser considerados como espaços para contemplação/fruição, (re) significando a experiência na urbe. No final do século XVIII, aparecem os primeiros jardins públicos voltados para o lazer.

Conforme Spirn (1995), no final do século XVIII, inicia-se na Europa, a Revolução Industrial, influenciando drasticamente variações espaciais, devido ao abandono das zonas rurais e à expansão das cidades, motivando uma série de transformações de ordem econômica, política, social e técnica. À medida que as cidades cresciam e a população demandava infraestrutura, aumentavam as queixas sobre alguns aspectos urbanos (trânsito, poluição atmosférica, mau cheiro, barulho, espaços de miséria, etc.) e diminuíam os espaços com fragmentos de natureza disponíveis para a população, que foram substituídos por casas, ruas, comércios, dentre outros. Assim, teve início a preocupação com reformas sanitaristas, por meio de leis de saúde pública, para a consecução de higiene/limpeza urbana e a construção de melhor infraestrutura. As queixas dos citadinos se estendiam também ao fato de a industrialização ter promovido o crescimento das cidades em detrimento dos espaços de natureza. Jardins particulares construídos no século XVII deram lugar às construções habitacionais e comerciais no século XVIII.

Vários modelos de urbanização fizeram parte do
conjunto de mudanças verificadas no Brasil do
limiar do século XX, o que resultou na formação
de novos cenários urbanos. Tais mudanças
tinham como um de seus objetivos, a perspectiva
de extinçãa das características relacionadas ao
passado escravista e rural de nossa sociedade.
Nos novos espaços urbanos, emergira um modo
de hábitos e comportamentos diferentes daqueles
vivenciados até o século XIX. Verificou-se, a partir
de então, novos modelos de comportamento, de
hábitos e de práticas populares, provocando o
surgimento de uma nova cultura popular urbana,
incluindo-se nestas "novidades", a propagaçãa
dos esportes modernos, [...]. Nas primeiras
décadas do século XX, houve no Brasil, uma
difusão das idéias favoráveis à prática da
educação física e, por extensão, das atividades
esportivas. Tal prática foi incentivada
especialmente nas escolas, e no meio militar.
Tanto professores, quanto médicos e integrantes
do poder público, idealistas da propaganda da
atividade física. (SILVA, 2010, p.89-90).

Em decorrência da expansão urbana e a introdução do ritmo da cidade industrial, com pouco tempo livre para se socializar e descansar, os parques urbanos surgem como demanda para as práticas de lazer. Ao mesmo tempo, compõem espaços amenizadores das estruturas urbanas, por meio de espaço de socialização e natureza, proporcionando melhor qualidade de vida para a população.

Essa ideia pode ser corroborada por Kliass (1993, p. 19) que apresenta o conceito de parque urbano, afirmando que: "[...] são espaços públicos com dimensões significativas e predominância de elementos naturais, principalmente cobertura vegetal, destinados à recreação.". No final do século XVIII, na Inglaterra, os parques urbanos surgem como fator 
urbano de relevância, todavia, seu desenvolvimento só culmina quase cem anos depois.

Scocuglia (2009) ressalta que os primeiros parques urbanos surgiram paralelamente à formação das cidades em fins do século XVIII, sendo o seu apogeu nas décadas de 1850 e 1860, na Europa e nos Estados Unidos.

No final do século XVIII, na Inglaterra, o parque surge como um fato urbano relevante e tem seu pleno desenvolvimento no século seguinte, [...]. No século XIX surgiram os grandes jardins contemplativos, os parques de paisagem, os parkways, os parques de vizinhança americanos e os parques franceses formais e monumentais. (SCALISE, 2002, s/p).

Apesar dessas motivações em outros países, 0 Brasil não foi impulsionado por tais mudanças comportamentais, pois, segundo Scocuglia (2009), o país ainda não possuía uma rede urbana expressiva e o sistema de parques funcionava como uma extensão do cenário das elites que apenas "repetiam" os modelos internacionais, ingleses e franceses. No início do século XIX, o Brasil é marcado por uma organização em sua estrutura, principalmente a partir da vinda da família real portuguesa em 1808.

Macedo (2003) afirma que tal reestruturação reflete nas velhas e pequenas cidades, reorganizadas para desempenhar novas e sofisticadas funções administrativas; uma dessas cidades é a antiga capital, o Rio de Janeiro, que incorpora tais funções, tornando-se rica em recursos e investimentos. 0 autor ressalta ainda que os parques, construídos em pequeno número, eram localizados em algumas das grandes cidades e restritos às áreas centrais e bairros de elite. De acordo com Kliass (1993) é a partir do final do século XIX que são criados os principais parques da cidade de São Paulo: Parque Villon, Parque Tenente Siqueira Campos (Parque Trianon), Parque Aclimação, Parque D. Pedro ll e Parque da Água Branca.

Na passagem do século XIX para o século XX, 0 parque, que antes era ricamente elaborado e decorado, torna-se também, segundo Macedo (2003), um elemento urbano comum, pois não só as principais capitais possuem belos parques, como também comunidades urbanas de médio e pequeno porte. Cita como exemplos os parques criados em estações de água nas cidades de Araxá e Poços de Caldas, ambos em Minas Gerais. $O$ autor destaca também que nesse período, surgem os primeiros parques privados do país, que ofereciam ao usuário, o acesso a exposições e zoológicos. Cita como exemplos o Jardim da Saúde, o Parque Antártica e o Jardim da Aclimação, todos em São Paulo.
De acordo com as exigências e as necessidades da sociedade emergente brasileira do século XIX, o país foi marcado por uma transição urbanística com transformação e modernização de suas cidades, na qual ocorreu uma reconfiguração urbana com ruas melhores distribuídas e arborizadas, edificações nos bairros, facilidade no tráfego, melhor uso da arquitetura, ajardinamento, calçadas elaboradas, dentre outros. Seguindo essa linha, principiou-se o uso da vegetação nativa na paisagem urbana, com a presença exuberante da flora brasileira, até então despercebida, valorizando os espaços urbanos.

Nesse contexto, os parques brasileiros foram criados com 0 objetivo de atender às elites emergentes e se basearam na figuração urbana internacional, especialmente inglesa e francesa, sem uma crítica profunda (MACEDO; SAKATA, 2003; MACEDO, 1999), destacando a influência das principais capitais do período: Londres e Paris. No entanto, os parques urbanos no Brasil, ao contrário dos europeus, não surgiram da necessidade social de espaços públicos para o lazer da massa urbana, mas sim para a elite. $O$ parque brasileiro, no século XIX, era totalmente alheio às necessidades sociais da massa urbana contemporânea, haja vista que esses indivíduos usufruíam de outros espaços, como várzeas, rios e riachos para a prática de lazer.

Ao longo da história, os parques urbanos assumem diferentes funções e usos, seguindo a influência da estrutura urbana, do fenômeno social e da preservação de áreas verdes. Eles não são submetidos a um padrão, pois se diferenciam quanto ao tamanho, funções, tipos de equipamentos, espaço de preservação ambiental e de socialização, dentre outros.

\section{METODOLOGIA}

Este estudo consiste em uma pesquisa histórica de cunho qualitativo que busca investigar a história do Parque Pelotense [Parque Souza Soares] em Pelotas no período de 1883 a 1916 a partir de informações bibliográficas e documentais.

As informações foram coletadas no acervo da Biblioteca Pública Pelotense, no Laboratório de Acervo Digital da UCPel, especificamente no acervo de Nélson Nobre Magalhães, no Instituto Histórico e Geográfico de Pelotas e do Rio Grande do Sul, no Museu da Comunicação Hipólito José da Costa, em Porto Alegre e na Biblioteca Riograndense de Rio Grande.

Segundo Oliveira (2007) a pesquisa bibliográfica consiste no estudo e análise de documentos de domínio científico, tais como livros, periódicos, enciclopédias, ensaios críticos, dicionários e artigos científicos, ou seja, consiste no "estudo direto em fontes 
científicas, sem precisar recorrer diretamente aos fatos/fenômenos da realidade empírica" (OLIVEIRA, 2007, p. 69). Desse modo, para esta pesquisa, foram utilizadas e as monografias "Parque Souza Soares: apenas lembranças", de Ana Lúcia Rassier e "Viagem na memória do Fragata: estudo sobre a história e cultura de um 'bairro cidade'", de Elisabete Oliveira e demais bibliografias sobre lazer e parques.

Além de pesquisa bibliográfica foi realizada uma pesquisa documental, que, segundo Oliveira (2007, p. 69) "caracteriza-se pela busca de informações em documentos que não receberam nenhum tratamento científico, como relatórios, reportagens de jornais, revistas, cartas, filmes, gravações, fotografias, entre outras matérias de divulgação". As fontes documentais foram fotografias e, principalmente, os jornais diários que circularam na cidade de Pelotas no período da existência do Parque Pelotense, ou seja, de 1883 até 1916. Os jornais pesquisados foram: Correio Mercantil (1883-1915), Onze de Junho (1883-1889), Diário de Pelotas (1883-1889), Diário Popular (18901916), Arauto (1904) e Opinião Pública (1912-1916).

Os jornais foram pesquisados sistematicamente, ou seja, jornal a jornal, ano a ano e mês a mês, o que possibilitou o acompanhamento da inauguração e do desenvolvimento do Parque. Zicman (1985) considera que uma das principais vantagens do jornal enquanto fonte é sua periodicidade, o que permite estabelecer a cronologia dos fatos históricos.

Além disso, os jornais, no período estudado, relatavam, com riqueza de detalhes, o cotidiano da cidade de Pelotas, pois, como afirma Loner (1998, p. 7), numa cidade pequena e requintada como Pelotas, "coisas que normalmente hoje não seriam reproduzidas [...] eram contadas nos mínimos detalhes, permitindo conhecer tanto o pitoresco do fato, quanto o lado cotidiano da vida das pessoas daquela época". Desse modo, os jornais tiveram um papel fundamental para a realização deste trabalho.

\section{RESULTADOS E DISCUSSÕES}

\subsection{Parque Pelotense: um espaço de lazer em Pelotas}

O Parque Pelotense foi aberto ao público em 1883 e era um dos principais "pontos de recreio" em Pelotas, no final do século XIX e início do século XX. Seu proprietário, José Álvares de Souza Soares, era imigrante português, nascido em Vairão no ano de 1846. Em 1874 fundou o "Laboratório Homeophatico Rio-Grandense", onde vendia algumas fórmulas importadas e outras manipuladas por ele mesmo (Onze de Junho, 03.02.1885, p. 2).
"O planejamento de fundação do Parque Pelotense e seu respectivo laboratório remontam ao ano de 1881, quando José Alvares de Souza Soares - mais conhecido como Visconde de Souza Soares comprou uma grande extensão de terras em Pelotas, cidade localizada ao sul do Rio Grande do Sul" (RASSIER, 2003, p. 25), na qual fez grandes investimentos para então inaugurar, dois anos após, 0 Parque Souza Soares conhecido, primeiramente, como Parque Pelotense. Este Parque possuía dentro de seus limites, o laboratório farmacêutico de Souza Soares (RASSIER, 2003; NUNES, 2007), que tratavase de uma expansão de seu Laboratório Homeopático Rio-grandense, fundado em 01 de julho de 1874, uma das primeiras farmácias da cidade de Pelotas.

José Alvares Souza-Soares (1846-1911) natural de Vairão (Vila do Conde) era filho de um médico e de uma farmacêutica, sendo o penúltimo descendente de uma numerosa família com nove filhos. [...]. A sua aposta na promoção da saúde e qualidade de vida humana manifestouse em variadas situações. [...] É na cidade de Pelotas que Souza-Soares cria o seu grande laboratório, inserido num magnífico parque [...], inaugurado em 1883 na presença do Imperador. (PEIXOTO, 2016, p. 8)

A inauguração do Parque ocorreu em dois de fevereiro de 1883 (Figura 1), no lugar denominado Vila do Prado, no Fragata, junto ao Prado Pelotense, a mais ou menos três quilômetros da cidade. O Parque foi construído com 0 objetivo de proporcionar divertimentos junto à natureza para a população de Pelotas e "excursionistas" que vinham visitar a cidade e é oficialmente o parque urbano mais antigo de Pelotas.

PARQUE PELOTENSE Como estava anunciado, efetuou-se ante-ontem a inauguração do Parque Pelotense, propriedade do ativo e honrado cavalheiro Sr. José Alvares Souza Soares, fundador do acreditado Laboratório Homeopatico Rio-grandense. $O$ estabelecimento estava embandeirado em todas as direções e apresentava uma brilhante perpectiva. Tres bandas de musicas colocadas em diferentes lugares, tocavam alternadamente e davam a diversão um aspecto animador e recreativo. Desde as 3 horas da tarde em diante, aproveitando os bondes e carros de praça, começou a populaçao a dirigir-se para aquele aprasivel local e a dissiminar-se por todas as avenidas e ruas do estabelecimento, de modo que pouco depois das 5 horas havia ali talvez mais de tres mil pessoas, destacando-se entre elas muitas famílias e cavalheiros da nossa sociedade. Era tão imponente a perspectiva que oferecia o Parque Pelotense com essa imensa 
multidão a passear por toda aparte e a deter-se aqui e ali para admirar os jardins, as edificações, lagos, chales, pontes rusticas, plantações, estufa, fontes, cascatas, finalmente todas aquelas belezas que a cada passo se encontram para atestar e exaltar a força de vontade, a inteligencia e atividade do homem que em tão pouco tempo e vencendo grandes dificuldades conseguiu transformar uma extensa e deserta campina em um estabelecimento produtivo e util á localidade. [...] (Correio Mercantil, 04.02.1883, p. 1).

Figura 1 - Parque Pelotense.

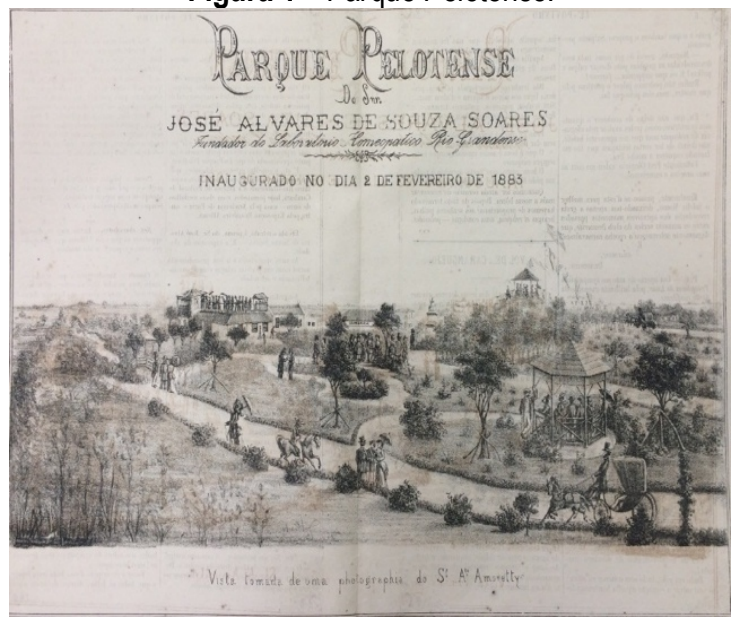

Fonte: Zé Povinho, 11.02.1883, n. 6.

Pela valorização da natureza e pela importância dada ao ar livre começaram a ser criados os parques campestres nos arredores da cidade de Pelotas. Dois deles localizavam-se no Fragata, local próximo da cidade, que tinha "prestígio de arrabalde aristocrático" (OSÓRIO, 1998, p. 305), o Jardim Ritter e o Parque Pelotense. O Jardim Ritter ocupava uma extensa área arborizada, ideal para as "tardes da estação calmosa", fazendo parte da fábrica de cerveja dos Srs. Ritter \& Irmão e era "um dos passeios prediletos da elite pelotense." (Diário de Pelotas, 26.01.1885, p. 2, Pelotas). Os outros parques, com menores dimensões, eram o parque Bosque de Bolonha e Campos Elysios, ambos no bairro da Luz. Porém, o parque mais expressivo do período, pelas suas dimensões e variedade de atividades, era o Parque Pelotense.

Os parques e jardins eram uma alternativa excelente de lazer para os que não podiam deixar a cidade em direção ao campo ou ao mar. Os parques brasileiros têm sua origem nos parques ingleses, que começaram a ser criados na Inglaterra ainda na segunda metade do século XVII.

Construídos a partir de uma concepção em que se procurava compatibilizar a natureza com a inteligência humana, estes parques - repletos de vegetação e vida animal - atraíam cada vez mais as famílias que os procuravam para a realização de caminhadas e picnics, e também desfrutar das atrações que porventura neles se apresentam, como bandas, fanfarras, acrobatas, malabaristas, espetáculos de fogos de artifício, etc. (SOARES, 2004, p. 28).

Esses parques apresentavam uma variedade de atrações vinculadas à natureza, ou seja, proporcionavam atividades "higiênicas", como passeios ao ar livre, passeios em lagos, jogos, corridas, entre outras atrações. A importância dada ao contato com a natureza está presente nos anúncios do Parque:

\begin{abstract}
VAMOS AO PARQUE! Como de costume efetua-se domingo 6 do corrente um brilhante concerto instrumental, no Parque Pelotense. Além desta agradável distração, os freqüentadores encontrarão uma grande variedade de divertimentos, cada um 0 mais higiênico e confortável. Na quadra doentia que atravessamos, uma visita ao parque, não é só um motivo de distração, mas uma vantagem para a saúde que precisa ser fortificada pelo ar puro e vivificante do campo. Á tarde efetuar-se-á a rifa de plantas. 0 administrador Ribeiro da Silva. (Diário de Pelotas, 06.12.1885, p. 3, Pelotas)
\end{abstract}

A importância do Parque para o lazer dos pelotenses pode ser demonstrada pela construção de uma nova linha de bondes de tração animal da Companhia Ferro Carril e Cais de Pelotas (Figura 2) com destino ao Fragata, no ano de 1876, oito dias após a inauguração do Parque. Nos períodos de maior "concorrência" eram colocados mais carros em funcionamento e desvios eram realizados a fim de facilitar 0 acesso a estes locais. "Por esta forma, teremos daqui em diante completa facilidade e rapidez de transporte para os divertimentos que se oferecem no ponto terminal da linha, sem 0 inconveniente das demoras e atropelamentos que se notaram por ocasião de grande concorrência." (Correio Mercantil, 01.04.1976, p. 1).

Parque Pelotense - Estrada do Fragata, onde termina a linha dos bonds - Quem, há pouco mais de doís annos, passou pelo campo aberto, onde se acha hoje o nosso pittoresco Parque, não poderá deixar de ficar surprehendido com a transformação que presencía. Com effeito! Ninguem imaginara que uma campina inculta, como aquella, se transformasse, como por encanto, em um extenso jardim, maior que o da praça Pedro II., com bosques, lagos navegaveis em pequenos barcos, ilhas, morros de grande elevação, grande praça arborisada, caramanchões, chalets, kiosques, estufa de acclimação, pontes, e assentos por toda à parte! Uma fonte de riquissima agua, só comparavel á melhor da serra! Mais de dois mil pés de arvores fructiferas, de primeira qualidade, havendo entre 
ellas muitas larangeiras de 10 annos, com toda sua capa primitiva! Grande horta; grandes lavouras dos principaes e mais necessarios cereaes. Vasto edificio, com uma extensão de 56 metros, onde brevemente vai funccionar 0 acreditado Laboratorio Homeopathico RioGrandense, com sua importante fabricação do afamado Peitoral Homeopathico de Cambará. Inda um outro edificio, com 28 metros de frente, destinado a uma Escola publica, que será costeiada pelo estabelecimento. O PARQUE PELOTENSE, pois, é a nossa primeira maravilha. É um estabelecimento que nos pertence, porque foi creado para nós. Visitemos, portanto, o nosso Parque, diaria ou semanalmente, como podermos e quisermos, interessendo-nos pelo seu engrandecimento, que é indubitavelmente a demonstração mais fiel do progresso d'esta importante localidade. (Onze de Junho, 18.04.1883, p. 2)

$O$ século $X I X$ foi um momento em que a população, além de vivenciar as preocupações com o saneamento, o aformoseamento e a higienização das cidades, também experienciou as transformações decorrentes da instalação de obras destinadas ao bem público, financiadas, na maioria das vezes, por capitais privados.

Outro aspecto a ser salientado é que o espaço servia como moradia para a família, prática muito comum nesse período, ou seja, a presença de grandes jardins privados nas moradias da pequena elite no século XIX, caracterizadas por pequenos palacetes construídos no meio de amplos jardins.

Figura 2 - Bonde na entrada do Parque.

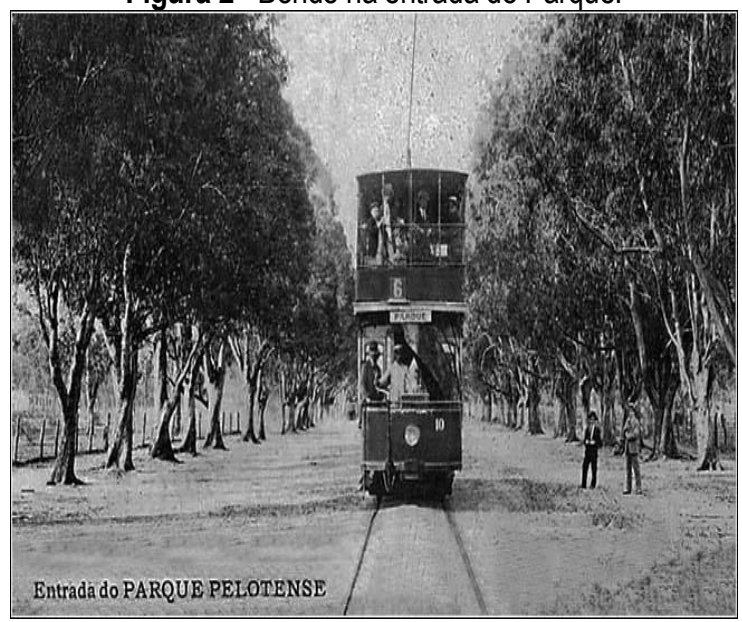

Fonte: Acervo Nelson Nobre/Pelotas Memória.

O Parque Pelotense, além de espaço para o lazer, moradia, era também ambientes de ensaio e pesquisa de plantas. Era situado na borda da cidade, como nas antigas cidades europeias, em terras muito ruins para arruamento ou construção.
Silveira (2009) destaca a carência de espaços públicos de lazer na cidade de Pelotas durante 0 século XIX. Essa carência de locais de recreação permeou as discussões da Câmara de Vereadores, restringindo a instalação de obras privadas, destinadas ao bem público, em praças, largos e parques. Observase, no final do século XIX e início do século XX, que os lazeres dos pelotenses estavam vinculados aos espaços privados, como o teatro e o cinema, os clubes recreativos e esportivos, as festas nas residências. Também se verifica que as atividades em áreas verdes se restringiam à Praça Cel. Pedro Osório, que era utilizada para retretas, passeios e espetáculos.

0 parque foi criado a partir de uma campina até ali inculta e árida, transformando-se numa área constituída por terrenos de lavoura, frondosos bosques, jardins, lagos, cascatas, praças com estátuas e avenidas. A parte lúdica não foi esquecida, surgindo assim no parque um ringue, vários jogos e aparelhos gimnodesportivos. 0 parque compreendia vários edifícios, uns de menor e outros de maior porte. Os edifícios principais eram ocupados pela Fábrica e Laboratório Homeopático e ainda por uma escola (PEIXOTO, 2016).

O parque possuía mais de 300 mil metros quadrados de área e compreendia, além do laboratório farmacêutico, granja, jardins com estufas, bosques, labirintos, fontes, praças, espaçosas ruas e passeios, restaurante, residências para os empregados, fábricas dos medicamentos, escola, capela e uma tipografia (SOUZA SOARES, [s.d.], p. 199). Conforme Oliveira (2007, p. 25), este português em pouco tempo conseguiu construir num local primitivo, uma obra grandiosa e maravilhosa, contemplada e admirada por todas as inúmeras pessoas que compareciam ao local. No parque havia muita diversão como carrossel, balanços, ringue de patinação e vários esportes como futebol, esgrima e outros mais, tudo a disposição da população, localizados na Praça dos Recreios (Figura 3).

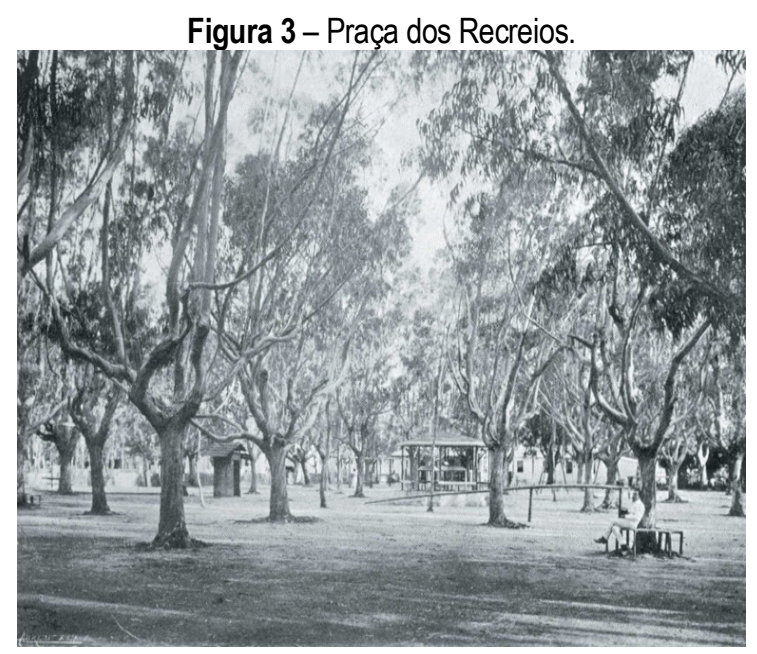

Fonte: Acervo Nelson Nobre/Pelotas Memória. 
Parque Pelotense - Este estabelecimento, 0 primeiro no seu genero, que existe na provincia creado para recreio dos habitantes d'esta cidade, conserva todos os dias uteis suas portas abertas e francas a todas as pessoas que 0 queiram visitar. [...] O PARQUE PELOTENSE é hoje o passeio favorito e dilecto da sociedade pelotense. Todos se admiram como de um terreno inteiramente inculto, de um campo aberto e raso, por onde há pouco mais de dois annos as carretas transitavam livremente, se formasse, como por encanto, um verdadeiro parque; 0 aprasível PARQUE PELOTENSE. O administrador - J. Simões. (Correio Mercantil, $1^{\circ}$ semestre de 1883)

Em relação ao Parque, principal local de recreio e de ócio dos pelotenses, Soares (2001) argumenta que a sua criação se insere em um conjunto de operações entendidas como "saneamento social" da cidade. Apesar de estar situado em uma propriedade particular, era aberto ao público. Enquanto espaço de reunião da população da cidade cumpriu diversas funções, sobretudo sociais: "permitia à burguesia local transmitir uma boa imagem e seu desejo de integração de todas as classes sociais, também se constituía num fator de controle social, pois a população trabalhadora era educada através dos hábitos higiênicos e polidos dos mais ricos." (SOARES, 2001, p.188).

Além da fábrica e laboratório, aquela grande extensão de terreno transformou-se em agradável ponto de atração turística, de lazer e entretenimento, com escola, capela, carpintaria, restaurante, lagos, cascatas, bosques, uma linha férrea e uma bem montada estrutura gráfica. Dali saíram, com esmerada feição, livros, panfletos, almanaques, cartazes, reclames, revistas e, segundo consta, até a edição inaugural do poemeto "Antonio Chimango", de Ramiro Fortes de Barcellos. (INSTITUTO HISTÓRICO E GEOGRÁFICO DO R. G. DO SUL, 2012, p.198).

Segundo testemunhos de descendentes do Visconde de Souza Soares, transcritos no trabalho de Rassier (2003, p. 71), "o Parque tinha grande importância não só para a cidade de Pelotas, mas, também, para todo Rio Grande do Sul, sendo uma referência em termos de apoio aos seus funcionários, oferecendo a eles escola, refeitório (onde podiam fazer duas refeições diárias) e proporcionando todas as condições de sanidade para o seu trabalho". Os depoimentos apontam que as homeopatias produzidas pelo laboratório do Parque eram consideradas eficientes e tinham uma grande demanda, procurados, inclusive, por cidadãos de outras localidades.

O Parque também era frequentado para estudos. Em seu interior havia a Escola Popular, na qual era ministrado gratuitamente 0 ensino primário para crianças carentes e para seus empregados, alfabetizando-os e, consequentemente, vinha aluno de longe, das chácaras e colônias para ali estudar.

O parque foi considerado uma alavanca para a popularidade das atividades de lazer e turismo que ofertava, trazendo muitas pessoas de fora para visitá-lo e, assim, captando muitos recursos para a cidade que Ihe sediava. Era um lugar muito conhecido por suas grandiosas e originais festas (RASSIER, 2003, p. 65).

PARQUE PELOTENSE Este aprazivel recreio, atraiu no domingo á tarde uma seleta $e$ numerosa concorrencia de senhoras e cavalheiros. Dia a dia encontram-se nova paisagem e novas distrações para entreter 0 espirito. Como estava anunciado, realizou-se, na praça do Parque uma corrida a pé entre um portugues e um espanhol, que dispertou geral curiosidade. $O$ portugues perdeu a partida. $O$ espanhol ganhou. A proposito diz um espectador sem 0 menor vislumbre de ofensa: - Está verificado que a Espanha é mais valente que Portugal. .. a correr. Até ao entrar da noite houve muito alvoroço e animação e todos se retiraram satisfeitos com as atenções do sr. Souza Soares e dos aprassiveis instantes que ali passarão. (Correio Mercantil, 20.02.1883, p.8).

No Parque ocorriam inúmeras festas, com muita musica, dança, bailes ao ar livre, etc.

A FESTA DE TODOS OS SANTOS - A excelente banda de musica Santa Cecília executará se o tempo permitir, as melhores peças de seu repertório nos jardins d'este aprazível centro de reunião da sociedade pelotense, que ali encontrará além de um ar puro e balsâmico, diferentes divertimentos do melhor gosto. (Correio Mercantil, Pelotas, 31. 10.1885).

O Parque apresentava diversos tipos de divertimentos, sendo um ponto bastante frequentado pelos moradores da cidade:

BAILE - Os apreciadores dos agradáveis bailes campestres, encontrarão no parque, elegantes salões, onde podem dançar, ao ar livre, bonitas havaneirass, polkas, walsas, etc., que a banda executará em seu novo e elevado coreto. PASSEIO MARITIMO - Fluctuando no caudaloso lago [...] acham-se a disposição dos apreciadores dos passeios marítimos, dois 
elegantes e soberbos cahiques. EM VELOCIPEDE - Alguns distinctos moços do commercio, pretendem, neste domingo, realizar uma interessante passeiata, em velocípede, por algumas das vistosas ruas do Parque, o que será de agradável e surprehendente effeito. A CAVALLO - Os cavalleiros que se quizerem exercitar em alguns jogos, tem a sua disposição superiores cavallos na Praça de recreio. ANDARILHO - Esta maravilha da mocidade, acha-se a disposição sómente do bello sexo e das crianças. GYMNASTICA Brevemente vão ser montados, vários apparelhos de gymnastica, para os amadores d'estes hygienicos exercícios. LABIRINTO Achando se quase concluído este divertimento, tão usado na Europa, está desde já á disposição de quem nelle se quizer perder. FONTE - Existem ruas bastante francas, que seguem á fonte, tanto para pessoas de pé como de carro ou a cavallo. AGUA FRESCA Aquelles que não quizerem ir á fonte, á água, encontraram da mesma, gratuitamente, no Expositor de plantas e quem os sirva. (Só pela água, vale a pena o passeio!) RESTAURANT Junto á Praça do Recreio, [...]. (Correio Mercantil, Pelotas, 14.12.1883, p. 2 e 3)

Evidencia-se que o Parque proporcionava diversas atividades de lazer junto à natureza, sendo um local bastante frequentado pela elite da cidade: eram realizados bailes ao ar livre; passeios em lagos, em velocípedes ou a cavalo; aparelhos de ginástica eram disponibilizados, para "higiênicos exercícios"; restaurante; concertos com bandas de música locais, entre outras atrações (Correio Mercantil, 14.12.1883, pp. 2-3).

Magalhães (1993, p. 157) descreve que no parque as atividades de lazer incluíam "músicas, cascatas, labirintos, morros, ringues, chalés, riachos e pontes", conforme demonstrado nos anúncios.

Segundo Scalise (2002, [s. p.]):

O parque, nesse período [século XIX], preocupase com as demandas de equipamentos para recreação e lazer, a necessidade de expansão urbana, o novo ritmo de trabalho, além da necessidade de criação de espaços amenizadores da estrutura urbana, bastante adensadas, com funções de "pulmões verdes", saneadoras, representando oásis de ar puro, de contemplação, estimulando a imaginação.

O Parque Pelotense foi construído, com o intuito de valorizar o espaço e constituir o lazer; no entanto, não era muito frequentado pela massa urbana e sim pelas elites. Como afirma Carvalho (2009) 0 sentimento de apreciação da natureza pode ser considerado uma sensibilidade burguesa, pois é essa parcela da população que dispõe de tempo e recursos para cultivar os novos hábitos de convívio e admiração da natureza.

Ressalta-se que o Parque Pelotense era um espaço representativo para o lazer dos citadinos e espaços de natureza que favorecem a sensação de liberdade. Para Serpa (2007) desde o século XIX até os tempos atuais, os parques representam um lugar de sociabilidade e urbanidade.

Os parques e os jardins, mais do que servir para 0 desfrute de alguns como parte integrante das grandes residências senhoriais, são criados, sobretudo, para satisfazer as exigências higiênicas, recreativas e educativas dos habitantes das cidades. $\mathrm{E}$, desta maneira, os requisitos desta arte não são somente de índole estética e técnica, mas também tem que atender a todo um conjunto de necessidades sociais (FARIELLO, 2000, p. 245).

Os parques contribuem "[...] para melhorar a qualidade da vida urbana e oferece aos habitantes das cidades espaços recreativos e de lazer 'festivo"' (SERPA, 2007, p. 82).

\section{PARQUE PELOTENSE É TAMBÉM EM PRESERVATIVO AS MOLÉSTIAS Presentemente, nós não temos; tão perto da cidade, lugar mais apreciável, comodo e saudável, do que o nosso Parque Pelotense! 0 ilustre e distinto corpo medico da cidade, reconhecendo as excelentes condições higienicas em que se acha este afamado estabelecimento, já recomenda aos seus clientes e amigos os passeios diários ao Parque Pelotense. E no entanto, ainda ha muita gente que tem o mau gosto de preferir sofrer, juntamente com sua família, as consequencias perigosas da vida sedentaria, neste tempo, ou de nao sairem da cidade, aspirando constantemente miasmas mais ou menos abundantes e nocivas, do que gozarem, ao menos uma vez por semana, um excelente e agradável passeio ao Parque Pelotense! Preferem ficar aborrecidos na cidade, indispostos e até mesmo doentes, do que a darem um passeio, tão agradável e higiênico e comodo! Domingo, se o tempo permitir, uma banda musical realizará um esplendido concerto no Parque Pelotense (Correio Mercantil, 22.01.1887).}

Além de diversão, festas e medicamentos 0 Parque possuía uma capela, que foi construída e ornamentada por artistas locais. Em 1903 era noticiada a benção da capela construída no Parque Pelotense, dedicada à Santa Luzia (Arauto, 13.12.1903, p. 2). 
No Parque Souza Soares encontrava-se um vasto labirinto, lugar com passagens confusas e intrincadas feitas com "cerca viva" (plantas utilizadas como cerca), no qual as pessoas se divertiam procurando umas as outras e tentando achar a saída do local, pois era muito difícil encontrá-la. Próximo ao labirinto, existia o Morro Santa Cecília, o qual era usado como mirante, tendo-se ampla visão do lugar e arredores, também era o local onde se realizavam consertos musicais (Figura 4).

Figura 4 - Morro Santa Cecília no Parque.

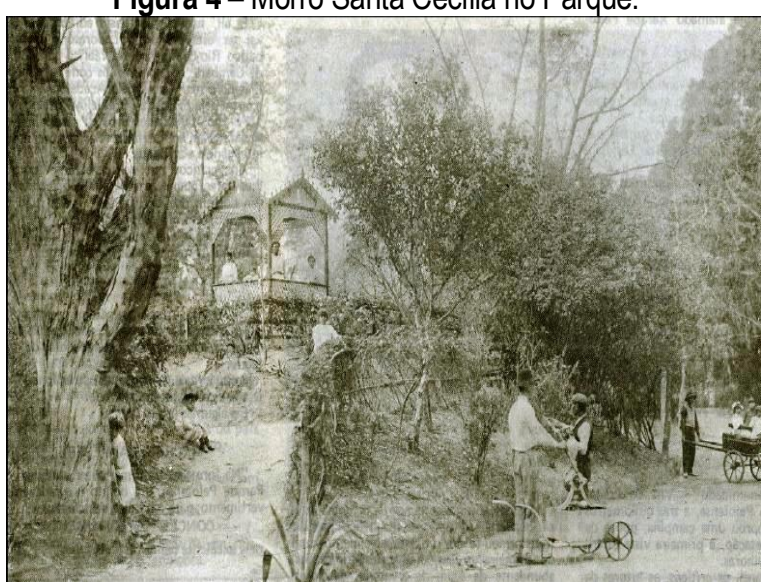

Fonte: Acervo Nelson Nobre/Pelotas Memória.

Também podemos observar na figura a seguir (Figura 5) familiares em momento de lazer no Parque Pelotense, ao som de uma vitrola, sob uma árvore.

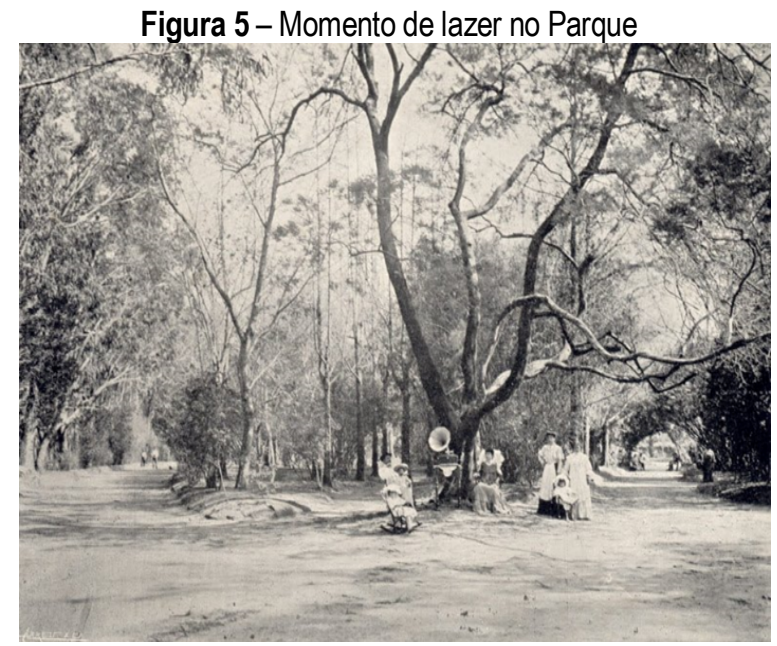

Fonte: Acervo Nelson Nobre/Pelotas Memória.

Pelas figuras, pode-se perceber a presença da elite pelotense:

Por esses espaços passeia a aristocracia, trajada especialmente para a ocasião, exibindo um vestuário à francesa e imitando os hábitos parisienses. Por suas alamedas desfilavam senhoras, cavalheiros e crianças ostentando 0 elaborado vestuário da época, com fraques pesados, vestidos com armações e muitas saias, e sombrinhas, a maior parte das roupas totalmente inadequada a um país tropical como o Brasil. (MACEDO; SAKATA, 2003, p. 23).

Reforçando essa ideia, Segawa (1996, p.15) descreve que ter presença no âmbito público é uma forma de "exibir pompa, ver homens e mulheres bem vestidos e bonitos, contar e ouvir novidades, assistir a apresentações musicais, mostrar filhas na busca de maridos, homens finos admirando e fazendo a corte a cortesãs". Diante do exposto, pode-se constatar que 0 Parque Pelotense era um espaço frequentado pela elite para ostentar um comportamento refinado.

No Parque compareceram visitas ilustres como a princesa Isabel e o conde $D^{\prime} E u$, o Marechal Deodoro da Fonseca, Olavo Bilac, Evaristo da Veiga, Antônio Feijó, Coelho Neto, o Bispo Dom Sebastião do Rio de Janeiro, o Ministro da Argentina e outros.

O filme mudo brasileiro "Os óculos do vovô" $e$ 1913, teve como cenário escolhido para as filmagens - Parque Souza Soares, o que demonstra a importância do Parque. O filme é o mais antigo filme de ficção brasileiro ainda preservado, dirigido pelo português Francisco Dias Ferreira dos Santos (18731937), foi originalmente produzido na cidade de Pelotas pela empresa Guarany Fábrica de Fitas Cinematográficas. Fragmentos dele foram resgatados na década de 1970 e a versão que se tem preservada possui pouco mais de quatro minutos.

0 parque era citado como "o mais viçoso e aprazível jardim que ainda aformoseia os arrabaldes de Pelotas" (Arauto, 20.12.1903, p. 1). Conforme relato de Leonor Almeida de Souza Soares e Carmen Souza Soares Reis:

Os bosques, jardins e avenidas arborizadas do parque Souza Soares logo se tornaram ponto de atração para a população de Pelotas e arredores, que passavam suas horas de lazer nos recantos da propriedade sendo por isso considerada como "o primeiro centro turístico em nosso estado". Praças, jardins, lagos, cascatas, uma ilha, caramanchões, coretos, um ringue de patinação, locais para jogos, aparelhos de ginástica, garantiam um ambiente saudável para os residentes e visitantes. (Leonor e Carmem apud MORAES, 2013, p.19).

Dona Marilia de Souza Soares Leite, já falecida, neta do Visconde de Souza Soares, comenta sobre o Parque no jornal Diário Popular:

[...] a vida no parque era uma maravilha, um paraíso. Tinha pomar, jardins, chafarizes, lagos, ilhas, avenidas, morros e, um labirinto onde era 
necessária a presença de um guarda para orientar as pessoas, caso contrário, as pessoas sem orientação não sairiam de lá, e a praça então, era uma beleza! Tinha balanços para adultos e crianças, trapézio, carrossel, gangorra, argolas, ringue de patinação, restaurante. Foi um Parque que serviu a várias gerações. (Diário Popular, 11.10.1987. 1987, p. 6)

De acordo com informações das bisnetas do fundador do parque Pelotense e primas em segundo grau, a professora universitária Leonor Almeida de Souza Soares e Carmen Souza Soares Reis, o parque:

foi aberto à visitação pública e recebia excursões de diversas cidades da região, servia de ponto para a difusão do folclore rio-grandense, nordestino e português. Nas festas dominicais se buscava conseguir recursos para um fundo destinado à abolição dos escravos. Souza Soares deu o exemplo e libertou na primeira dessas festividades os que possuía e todos passaram a ser empregados livres. "Isto ocorreu antes da abolição pela princesa Isabel", frisa 0 tataraneto Soares Filho. (NUNES, 2007, s/p).

O parque Souza Soares sofreu grande declínio depois que seu fundador transferiu residência para Portugal em 1901 acompanhado de sua segunda esposa e de sete filhos menores, deixando seus dois filhos mais velhos a frente do empreendimento comercial.

Seu filho Leopoldo Álvares de Souza Soares que ficou a frente da parte comercial e seu filho Dr. Miguel de Sousa Soares químico farmacêutico responsável pela parte de fabricação dos medicamentos lutaram com grande dificuldade decorrente da situação do país após a Primeira Guerra Mundial, tendo ao mesmo tempo que arcar com grande parte do sustento da nova família do pai em Portugal (MORAES, 2013, p. 34).

Em 1916 o Parque foi arrendado pela empresa Força e Luz, a qual realizou diversas obras de remodelação e a instalação de atrativos (Opinião Pública, 14.12.1916, p. 2), passando a não ser administrado pela família Souza Soares.

Logo, os filhos ficariam ainda mais onerados com todos os encargos do negócio, chegando com dificuldade à década de 1950 quando houve a falência da firma.

Após um caminho de diversas bifurcações - que incluem questões familiares e a abertura de um novo laboratório na cidade do Porto em Portugal - 0 Parque Pelotense entrou em decadência. Embora não exista uma data precisa para o seu fechamento, após um processo de inventário iniciado no ano de 1956, foi então decretada a falência da Sociedade
Souza Soares no Brasil (RASSIER, 2003, p. 46-51; SOUZA SOARES, [s.d.], p.187-191).

$\mathrm{Na}$ década de 1970 a propriedade foi partilhada entre os herdeiros, a maioria dos quais vendeu seus lotes ao mesmo comprador que não manteve nada do que restava da mesma, loteando a área para casas populares.

Miguel morreu em 1961 e seu filho Jorge no ano de 1979. Parte da área onde tudo começou, que ainda era ocupada pelos descendentes, no entanto, foi alvo de depredação. "A ladroeira e 0 vandalismo de que foram vítimas a casa, a capela e a fábrica ocorreram justamente quando meu tio (Jorge) estava sendo velado, no mesmo dia em que morreu", conta Carmen. Conforme relatos da família, diversos caminhões do município participaram do furto. Sumiram as imagens e as alfaias da capela, o altar, as grades de comunhão e até as tábuas do assoalho. Do laboratório e da fábrica tudo o que podiam levaram também. Parte da casa de Miguel foi revirada, especialmente o escritório, onde estava uma coleção de armas, relógios antigos e grande variedade de objetos. "Tudo isso foi perpetrado na calada da noite, enquanto meu tio estava sendo velado na capela do cemitério", frisa Carmen. (NUNES, 2007, s/p)

A bisneta do visconde, Leonor, e o sobrinho dela, Sérgio Almeida de Souza Soares Filho (tataraneto do Visconde) não escondem o orgulho das atitudes e das ações desenvolvidas por ele na época nas mais diversas áreas onde se destacou. "Ele foi um grande visionário, um progressista. 0 visconde foi pessoa de grande vulto", afirmam (NUNES, 2007, s/p).

Ao se analisar a trajetória do Parque Pelotense, quando as áreas verdes das cidades passam a receber um status de local higiênico e saudável em contraposição à desordem encontrada na vida urbana, dando um sentido elitizado a estes espaços verdes, podemos verificar a importância do Parque Pelotense para 0 lazer em Pelotas, notadamente devido a sua dimensão e diversidade de atrações. Ele foi o mais importante espaço verde já construído na cidade, adquirindo muitas das principais funções e usos que os parques urbanos modernos hoje possuem.

Importante destacar, porém, que, ao longo dos anos, a partir do início do século XX, os grandes espaços verdes de Pelotas foram dando lugar ao crescimento da cidade, desaparecendo após serem loteados para a construção de moradias. Neste cenário, a população de Pelotas passa a viver 0 restante do século XX sem mais possuir grandes áreas verdes, possuindo somente algumas praças em seu espaço urbano, além dos canteiros encontrados em suas principais avenidas. 


\section{CONSIDERAÇÕES FINAIS}

Um dos primeiros e principais "pontos de recreio" em Pelotas, pelas suas dimensões e variedade de atividades, foi o Parque Pelotense, aberto ao público em 1883, posteriormente denominado Parque Souza Soares.

Souza Soares cria seu laboratório farmacêutico e, logo, o Parque Pelotense em seu entorno. Pode-se supor que por ser ele um homeopata, estava articulado a um discurso da época cuja preocupação era com a melhoria da qualidade de vida da população das cidades, assim incentivando novos hábitos e comportamentos, relacionados às atividades ditas higiênicas, tais como o contato com a natureza e a prática de atividades físicas.

O Parque Pelotense, um parque privado surgiu inspirado em cenários europeizados, com fontes, quiosques, pórticos, esculturas, pontes, bosques, labirintos, praças, jardins, lagos, cascatas e restaurante, apresentando, assim, várias opções de lazer para a população pelotense e para os visitantes. Nestes espaços disponibilizava carrossel, balanços, rinque de patinação, vários jogos, bailes ao ar livre, concertos com bandas de música locais, passeios em velocípedes ou a cavalo, e inúmeros equipamentos voltados ao lazer como aparelhos gimnodesportivos, prática de vários esportes como futebol, esgrima.

Assim, no parque eram realizadas diversas atividades de lazer - culturais, físicas, contemplativas, sociais, educativas, artísticas e ambientais. Ressaltase que, ao usufruir desse espaço, a população se divertia, descansava, se sociabilizava e trocava conhecimento com familiares e amigos, rompendo com o universo do cotidiano.

Tais práticas de recreio, divertimento e ócio estão inseridas em um contexto mais amplo, sendo uma possibilidade da elite diferenciar-se. Neste sentido a utilização do Parque revela-se como símbolo de distinção social para os pelotenses.

Principalmente nos finais de semana o Parque Pelotense era muito frequentado, sendo um dos principais atrativos da cidade de Pelotas. Era um verdadeiro e significativo centro de atrações turísticas no Rio Grande do Sul. Foi, portanto, um atrativo tanto para moradores quanto para turistas, propiciando um espaço com diversas atividades e fragmentos de natureza no meio urbano. Este local teve a função de conduzir os sujeitos à sensação de descanso e de entretenimento, seja pela recriação do contato com a natureza, seja pela oferta de atividades de lazer dotadas de elementos lúdicos.

Com o fechamento do Parque, que ocorreu, principalmente, a partir da falência do Laboratório, Pelotas passou a contar com poucos espaços verdes destinados ao lazer da população, limitando-se às praças e ao balneário Laranjal.

Ainda hoje, Pelotas não conta com um parque desse porte. No caso do objeto aqui analisado, podese depreender que dados sobre a história do Parque Pelotense são de extrema importância, pois desse empreendimento erigido sobre uma vasta área e que não mais existe, restam apenas algumas lembranças e alguns vestígios.

Através da compreensão acerca do surgimento e da trajetória do Parque Pelotense de Pelotas e seu uso para o lazer pôde alcançar alguns fragmentos desse passado esvanecido. São vestígios que funcionam como suportes memoriais por meio dos quais, com concepções e influências presentes, atualiza-se um passado que não se vivenciou, mas que se tem a possibilidade e 0 privilégio de aproximar-se.

\section{REFERÊNCIAS}

CARVALHO, I. C. de M. Paisagens, historicidade e ambiente: as várias naturezas da natureza, Confluenze, Bologna, v. 1, n. 1, p. 136-157, 2009.

CSERGO, J. Extensão e mutação do lazer citadino, Paris, século XIX-princípio do século XX. In. CORBIN, A. História dos Tempos Livres. $O$ advento do lazer. (Tradução de Telma Costa). Lisboa: Teorema, 2001, p. 137-202.

CORBIN, A. Do lazer culto à classe do lazer. In: História dos Tempos Livres. 0 advento do lazer. (Tradução de Telma Costa). Lisboa/Portugal: Teorema, 2001, p. 59-90.

FARIELLO, F. La arquitectura de los jardines: de la antigüedad al siglo XX. Madrid: Celeste, 2000.

GILL, L. A. A cura sob suspeita: a presença de espíritas, feiticeiros, homeopatas e licenciados em Pelotas (RS) - 1891-1930. IX Encontro Estadual de História. 2008. Disponivel

em: http://eeh2008.anpuhrs.org.br/resources/content/anai s/1212353245 ARQUIVO TextofinalANPUH2008LorenaAlmeidaGill.pdf. Acesso em: 24.04. 2016.

GOMES, R. $O$ ócio da Lisboa de 1900 - tradição e mudança nas práticas e representações do ócio urbano. Actas do Congresso Mundial do lazer/World Leisure Congress, 3-5 de Junho de 1992. Lisboa: Edições do Instituto de Ciências Sociais da Universidade de Lisboa, 1992.

INSTITUTO HISTÓRICO E GEOGRÁFICO DO RIO GRANDE DO SUL. Discurso de Recepção. Fausto José Leitão Domingues. Revista do Instituto Histórico e Geográfico do RS. 2012, n. 146.

KLIASS. Rosa Grena. Parques urbanos de São Paulo e sua evolução na cidade. São Paulo: Pini, 1993.

MACEDO, S. S; SAKATA, F. G. Parques Urbanos no Brasil (Brazilian Urban Parks). São Paulo: Edusp, 2002. 
MACEDO, S. S. Parques Urbanos no Brasil. Editora da Universidade de São Paulo: Imprensa Oficial da Universidade de São Paulo. São Paulo, 2003.

MAGALHÃES, M. O. Opulência e Cultura na Província de São Pedro do Sul. Um estudo sobre a história de Pelotas. Pelotas: Ed. UFPel, 1993.

MARRONI, F. V. Pelotas (re)vista: a Belle Époque da cidade através da mídia impressa. Tese (Doutorado em Comunicação e Semiótica) - Pontifícia Universidade Católica de São Paulo, São Paulo, 2008.

MELO, M. I. O. Parques Urbanos, a Natureza na Cidade: Práticas de Lazer e Turismo Cidadão. Mestrado Profissional em Turismo. Universidade de Brasília. Brasília, 2013.

MORAES, F. R. Um Estudo Sobre a Conservação do Altar de Santa Luzia. Monografia Bacharelado em Conservação e Restauro de Bens Móveis. UFPEL. Pelotas/ RS, 2013.

NUNES, I. A. Cultura: Injeção de ânimo no resgate da história. Diário Popular. 09.12.2007.

OLIVEIRA, M. M. Como fazer pesquisa qualitativa. Petrópolis, Vozes, 2007.

OLIVEIRA, E. P. de. Viagem na memória do Fragata: estudo sobre a história e cultura de um "bairro cidade". Monografia apresentado no curso de Especialização em Patrimônio Cultural. Programa de Pós-graduação em Artes. Universidade Federal de Pelotas, 2007.

OSORIO, F. A Cidade de Pelotas. 3.ed.rev. Pelotas: Armazém Literário, 1998. (Coleção Cidade de Pelotas, 2).

PEIXOTO, P. T. Património de origem filantrópica contributo dos brasileiros. Revista Lusíada. Universidade Lusiada (Porto), 2016. Disponível em: http://revistas.lis.ulusiada.pt/index.php/fa/article/d ownload/314/292. Acesso: 18.04.2016.

PORTER, R. Os ingleses e o lazer. In: CORBIN, Alain. História dos Tempos Livres. O advento do lazer. (Tradução de Telma Costa). Lisboa/Portugal: Teorema, 2001, p. 19-58.

RASSIER, A. L. P. L. Parque Souza Soares: apenas lembranças. Trabalho de Conclusão de Curso (Especialização em Patrimônio Cultural: conservação de artefatos) - Universidade Federal de Pelotas, Pelotas, 2003

SCALISE, W. Parques Urbanos - evolução, projeto, funções e uso. Revista Assentamentos Humanos.
Marília, v. 4, n. 1, 2012, p.17-24. Disponível em: http://www.unimar.br/feat/assent humano4/parques.h tm Acesso em: 05. 04.2015.

SCOCUGLIA, J. B. C. O Parc de La Tête d'Or. patrimônio, referência espacial e lugar de sociabilidade. Arquitextos, São Paulo, 13.03.2009. Vitruvius. Disponível em: http://www.vitruvius.com.br/revistas/read/arquitextos/1 0,113/20 Acesso em: 05. 04.2015.

SEGAWA, H. Ao amor do público: jardins no Brasil. São Paulo: Studio Nobel: FAPESP, 1996.

SERPA, A. O Espaço Público na Cidade Contemporânea. São Paulo: Editora Contexto, 2007.

SILVA, J. da. A difusão das atividades esportivas como um dos instrumentos para a modernização das cidades. Fronteiras, Dourados, MS, v. 12, n. 22, p. 89-99, jul./dez. 2010.

SILVEIRA, A. M. da. De fontes e aguadeiros à penas d'água: reflexões sobre o sistema de abastecimento de água $e$ as transformações da arquitetura residencial no final do século XIX em Pelotas - RS. Tese (Doutorado em Arquitetura) - Universidade de São Paulo, São Paulo, 2009.

SOARES, L. A. de; REIS, C. S. S.. Parque Souza Soares. In: LONER, B.; GILL, L. A.; MAGALHÃES, M. O. (Orgs.). Dicionário de História de Pelotas. Pelotas: Editora da UFPel, 2010.

SOARES, L. C. A comercialização do lazer e a emergência dos espaços públicos de diversão na Inglaterra do século XVIII. Pós-História, Revista do Programa de Pós-Graduação em História, Assis-SP, n. 12, p. 1734,2004

SOARES, P. R. R. Modernidade Urbana e Dominação da Natureza: o saneamento de Pelotas nas primeiras décadas do século XX. História em Revista, Pelotas, v.7, 2001

SOUZA SOARES, V. O Novo Médico. 2 ed. Portuguesa. Porto (Portugal): Estab. Indust. Pharmaceut. [s.d.].

SPIRN, A. W. O jardim de granito: a natureza no desenho da cidade. Tradução: Paulo Mesquita Pellegrino. São Paulo: Edusp, 1995.

ZICMAN, R. B. História através da imprensa - algumas considerações metodológicas. Projeto História, Revista do Programa de Estudos Pós-Graduados em História e do Departamento de História - PUCSP, São Paulo, n. 4, p. 89-102, jun./1985.

\section{Processo Editorial / Editorial Process}

Editor Chefe/Editor-in-chief: PhD Thiago D. Pimentel (UFJF).

Recebido em 31 de Janeiro de 2018; aceito em 12 de Junho de 2018; publicado online em 09 de Julho de 2018.

Received on January 31, 2018; accepted on June 12, 2018, published online on July 09, 2017.

Artigo original / Original article. Seção revisada por pares / Double bind review section. 